\title{
La sustitución de importaciones pesqueras y el desarrollo de la pesca comercial marítima en Argentina (1930-1965)
}

\section{The substitution of fish imports and the development of commercial fishing in Argentina (1930-1965)}

José Antonio Mateo ${ }^{1}$ http://orcid.org/0000-0002-2074-3392

${ }^{1}$ Consejo Nacional de Investigaciones Científicas y Técnicas - INES ARGENTINA.

Email: jamateo@fceco.uner.edu.ar

\begin{abstract}
Resumen
La economía argentina posterior a 1930 ha sido objeto de una extensa y rica producción historiográfica. A ella nos remitimos para configurar el período histórico y articularlo con el desarrollo industrial pesquero nacional. El objetivo del presente trabajo es analizar las transformaciones que sufrió la industria pesquera argentina a través de tres momentos del proceso de industrialización dirigida por el Estado. La primera fue de improvisaciones obligadas por la depresión que siguió a la crisis de los años treinta. La segunda, que se inició con la Segunda Guerra Mundial, tuvo como componente una política de Estado hacia el mercado interior, caracterizada por una demanda internacional inesperada de una especie, el tiburón, y sus componentes vitamínicos, más la llegada al país de inmigrantes belgas con nuevas tecnologías para la pesca de ultramar. En la tercera, esta forma de pesca comenzó a hacerse hegemónica vinculada a una especie, la merluza, y esencialmente al mercado exterior. En todos los casos el puerto de Mar del Plata fue, en el sudeste de la provincia de Buenos Aires, el vértice concentrador mayoritario de la actividad pesquera argentina extractiva y de su procesamiento para la comercialización.
\end{abstract}

Palabras claves: industria sustitutiva, pesca, comercialización, Argentina.

\begin{abstract}
The Argentine economy after 1930 has been the object of an extensive and rich historiographical production. We refer to it to configure the historical period and articulate it with the national industrial fishing development. The objective of the present work is to analyze the transformations that the fishing industry suffered in Argentina through three moments of the industrial process directed by the State. The first was of improvisations forced by the depression that followed the crisis of the years 1930. The second one, which began with the World War II, had a politics of State towards the home market, but it was crossed by an international unexpected demand of a species, the shark, and his components of vitamins and the arrival to the country of Belgian immigrants with new technologies for the fishing open sea. In the third, this form of fishing began to become hegemonic linked to a species, hake and essentially to the foreign market. In all cases, the port of Mar del Plata was, in the southeast of the province of Buenos Aires, the main concentrator of the extractive Argentine fishing activity and its processing for commercialization.
\end{abstract}

Keywords: substitute industry, fishing, commercialization, Argentina.

Recibido: 18 julio 2017. Aceptado: 30 noviembre 2018 


\section{Introducción}

La "Gran Depresión” del siglo XX obligó a un grupo de países latinoamericanos a desarrollar, desde principios de la década del treinta, políticas autónomas que Carlos Díaz Alejandro ha denominado como "una serie de improvisaciones más o menos obligadas por las circunstancias" (Diaz Alejandro, 1979, p. 149). Con la Segunda Guerra Mundial la improvisación fue dando paso a políticas de Estado; una orientada al mercado interno seguida de otra abierta dirigida a los mercados internacionales. Tras una experiencia mercado-internista de desarrollo endógeno, y tras un golpe de Estado que proscribió al gobierno que había impulsado aquel modelo, se convocó al capital externo como motor del desarrollo.

La historiografía acerca del período es rica en argumentaciones y debates que no se han detenido (Villanueva, 1972; Llach, 1984; Rougier, 2001; Gerchunoff y Antúnez, 2002; Balsa, 2004; Míguez, 2005), los cuales señalan las contradicciones políticas y económicas del período y, sobre todo, el contexto de antecedentes a la llegada del primer peronismo hacia 1945. Los análisis de sectores productivos son sin embargo escasos, como lo son en general aquellos vinculados a la actividad pesquera en la economía argentina. Nos proponemos aquí el análisis del desarrollo industrial pesquero acaecido a partir de las políticas económicas que siguieron a la crisis de 1930.

El objetivo del presente trabajo es analizar las transformaciones que sufrió la industria pesquera argentina a través de tres momentos del proceso de industrialización dirigida por el Estado, término que creemos más exacto - ya que contiene las dos características distintivas: el foco creciente en la industrialización como eje del desarrollo y la ampliación significativa de las esferas de acción del Estado en la vida económica y social que el más imperfecto - pero más usado y reconocido- de "industrialización por sustitución de importaciones" (Bértola y Ocampo, 2010, p. 10).

Si bien el proceso no finaliza en 1965, podemos advertir claramente en el período analizado los tres momentos centrales del mismo. El primero se caracteriza por el ímpetu industrialista que se puso en marcha durante los gobiernos conservadores de la "Concordancia" (1930-1943), en los cuales se generaron las estrategias que pondrán a las industrias no tradicionales en la ruta exportadora. En ella se destacaron las intenciones del equipo económico (Raúl Prebisch, Antonio De Tomaso y sobre todo Federico Pinedo) en orientar el comercio hacia los Estados Unidos con el destino de incipientes y particulares exportaciones pesqueras. El segundo estuvo ligado a la política mercado-internista del peronismo para la industria pesquera (1943-1955). Finalmente, dentro de la etapa desarrollista (iniciada en concreto en 1958 y última del proceso de industrialización dirigida por el Estado), la coyuntura dio lugar al definitivo acceso de la industria del pescado congelado argentino en el mercado internacional.

El sector pesquero argentino se desarrolló casi con sigilo durante el siglo XX, hasta transformar un país "con pesca" en un país "pesquero", con la particularidad de serlo mientras su población apenas consumía entre 4 y $5 \mathrm{~kg}$ de pescado por habitante al año (Mateo, 2011b, p. 11). En este sentido, la pesca comercial marítima se presentaba, por un lado, como una industria extractiva que fácilmente podía sustituir la mayor parte de aquello que el rubro importaba y, por otro, una fuente de divisas apreciable por tener un escaso mercado interior. Estas claves de la política económica, en momentos críticos de la economía del país, no pasaron inadvertidas para un pequeńo número de pequeños productores pesqueros, intermediarios y expendedores de productos marítimos. El desarrollo en esta etapa no fue el producto de resultados inmediatos y peculiares de las políticas, sino del esfuerzo sostenido de quienes la llevaron a cabo. Por otra parte, las variaciones de la actividad pesquera a lo largo del período permiten vislumbrar el comportamiento relativamente autónomo de los industriales del sector (ver Cañete, 2011).

\section{Intervención estatal y exportaciones pesqueras}

Las políticas oficiales que siguieron a la crisis iniciada en 1930 intentaron mantener la estructura productiva afectada por esta con instituciones tales 
como las Juntas Reguladoras de diferentes producciones (las más importantes de ellas, granos y carnes) mediante precios sostén, evitar el sangrado de divisas interviniendo en el mercado de cambios a partir de una Comisión de Control de Cambios que establecía prioridades para el destino de las divisas provenientes de retraídas exportaciones y regular el crédito con la creación del Banco Central y el establecimiento de los encajes bancarios. Estas medidas a su vez buscaron (o encontraron) el incentivo para diversificar e industrializar exportaciones no tradicionales y ampliar los mercados externos.

Además de las medidas cambiarias y regulatorias que se sancionaron en esta etapa, cabe señalar la sustanciosa producción censal que se llevó a cabo entre 1933 y 1941. La misma tenía por objeto comprobar el grado de desarrollo y las potencialidades de las industrias regionales que devendrían de las mencionadas juntas. Así, se realizó el Censo Nacional de Yerba Mate (1933/34), Censo Algodonero (1935/36), Censo Nacional de Vinos (1936/37/39), Censo Nacional de Floricultura (1939) y el Censo de Pesca y Caza Marítima (1941), además de la publicación de los resultados de las encuestas industriales realizadas en 1935, 1937, 1939 y 1941 (Novick, 2004).
El Censo de Pesca y Caza Marítima dio cuenta de las variaciones y especializaciones regionales que la actividad pesquera ya presentaba en 1940 y en 1941, y evidenció una industria que se desarrollaba desde principios del siglo XX en cada una de sus especialidades. El censo contempló la actividad marítima y la fluvial, pero el mayor énfasis estuvo puesto en la industria en la ciudad de Mar del Plata, en el sudeste de la provincia de Buenos Aires, cuya base principal era la salazón y elaboración de la anchoíta (Engraulis anchoita), especie que aglutinaba la casi totalidad de la actividad. La preponderancia de esta especie llevó a los censistas a estimar conveniente "realizar el censo de la parte industrial en noviembre por ser el momento en que se intensificaban las tareas de pesca, ya que la anchoíta, principal renglón de la industria, afluye a las costas de Mar del Plata, máximo centro de producción del país". El censo revela la base que daría origen a la industria de productos de la pesca (Mateo y Yurkievich, 2010).

Para 1941 la pesca marítima y fluvial argentina presentaba la siguiente estructura (Tabla 1):

Las actividades en los distintos rubros señalados comenzaron casi simultáneamente a fines del siglo

Tabla 1. Cantidad de establecimientos industriales individualizados por rubros de industria.

\begin{tabular}{|c|c|c|c|c|c|c|c|c|}
\hline Rubros & Capital & $\begin{array}{c}\text { Buenos } \\
\text { Aires }\end{array}$ & Entre Ríos & Santa Fe & Chubut & $\begin{array}{c}\text { Tierra del } \\
\text { Fuego }\end{array}$ & $\begin{array}{l}\text { Plataforma } \\
\text { continental }\end{array}$ & Total \\
\hline $\begin{array}{l}\text { Conservas } \\
\text { de pescado }\end{array}$ & 6 & 55 & & & & 1 & & 62 \\
\hline $\begin{array}{l}\text { Pescado, } \\
\text { guano, } \\
\text { aceite, } \\
\text { harina }\end{array}$ & & 8 & 5 & 1 & & & & 14 \\
\hline $\begin{array}{l}\text { Ballena, } \\
\text { aceite, } \\
\text { harina de } \\
\text { huesos y } \\
\text { guano }\end{array}$ & & & & & & & 1 & 1 \\
\hline $\begin{array}{l}\text { Lobos, } \\
\text { aceite, } \\
\text { harina, } \\
\text { cueros }\end{array}$ & & & & & 4 & 1 & & 5 \\
\hline $\begin{array}{l}\text { Guano de } \\
\text { pescado }\end{array}$ & & 1 & & & & & & 1 \\
\hline Total & 6 & 64 & 5 & 1 & 4 & 2 & 1 & 83 \\
\hline
\end{tabular}

Fuente: Censo de Pesca y Caza Marítima, ley 12.343/41, Ministerio de Agricultura y Ganadería de la Nación, Buenos Aires, 1941. 
XIX; sin embargo, fue la de aceite de pescado y de cetáceos la que registra la más temprana participación en el comercio exportador.

La única productora de aceite de animales marinos era la "Compañía Argentina de Pesca", una sociedad anónima fundada en 1904, cuyo capital inicial estaba integrado por accionistas argentinos (como el industrial Ernesto Tornquist) y noruegos (como el "explorador" Carl Anton Larsen). En realidad, la compañía se creó a instancias del gobierno noruego. La sobreexplotación de la ballena en el Atlántico Norte y la concentración de los cetáceos en el hemisferio sur impulsaron a inversionistas de ambos países a emprender el negocio ballenero. La explotación se realizaba en el puerto de Grytviken, en las islas Georgias del Sur y rendía importantes dividendos, pero, a fin de evitar altos costos de flete y transbordo, la compañía transportaba el aceite en una fragata de su propiedad directamente a Europa. La compañía funcionó hasta 1964, pero ya a partir de 1930 su accionar era bastante confuso. Los Anuarios de Comercio Exterior (Tabla 2) registran operaciones relacionadas con el negocio ballenero identificables unos pocos años, ya que a partir de 1935 se asimilan los aceites y guanos de pescado y cetáceos. Estos productos van a liderar el comercio exterior pesquero durante buena parte del período analizado, por lo menos hasta que el aceite de tiburón se convierta, sobre todo por su alto valor, en el principal producto exportado por el sector pesquero y origine la transformación de este (Dirección General de Estadística de la Nación, 1933 y pass.).

La captura de la merluza, el producto insignia en el mercado exterior de Argentina, era estacional y se practicaba en diferentes lugares según la época del año, dentro de una franja marítima bastante acotada; en invierno junto a la desembocadura del río de la Plata, en otońo y primavera se llegaba hasta Mar del Plata y en verano la pesca se realizaba entre los paralelos $39^{\circ}$ y $51^{\circ}$ de latitud Sur. Los barcos solamente recalaban en Mar del Plata cuando los cardúmenes se encontraban en el paralelo $42^{\circ}$, pero el precio del hielo y el envío del pescado por tren resultaban antieconómicos y muchas veces se corría el riesgo de perder el producto por degradación antes de alcanzar los mercados (López, 1954).

La falta de infraestructura necesaria para la conservación del pescado era una preocupación constante para los productores, ya que la carencia de frigoríficos cercanos a los puertos de desembarque los obligaba a comercializar rápidamente el producto, lo que significaba aceptar los precios y las condiciones de los intermediarios. Para 1940 había 394 expendedores de pescado en todo el país, cifra que incluye locales de venta y puestos en ferias barriales y en mercados. Diecisiete mayoristas distribuían el pescado a los expendedores de la capital y del interior, además eran propietarios de comercios minoristas y de puestos en los principales mercados porteńos.

Tabla 2. Exportación de guano y aceite de pescado y cetáceos.

\begin{tabular}{|l|c|c|c|c|c|c|c|}
\hline \multicolumn{1}{|c|}{ Ańos } & $\mathbf{1 9 3 0}$ & $\mathbf{1 9 3 5}$ & $\mathbf{1 9 4 0}$ & $\mathbf{1 9 4 5}$ & $\mathbf{1 9 5 0}$ & $\mathbf{1 9 5 5}$ & $\mathbf{1 9 6 0}$ \\
\hline $\begin{array}{l}\text { Volumen } \\
\text { total de las } \\
\text { exportaciones } \\
\text { (en Tm) }\end{array}$ & 258,6 & $3.108,13$ & $1.337,95$ & $9.896,4$ & $2.046,82$ & 894,72 & $1.142,96$ \\
\hline $\begin{array}{l}\text { Volumen } \\
\text { exportado } \\
\text { de aceite y } \\
\text { guano } \\
\text { (en Tm) }\end{array}$ & 258,05 & $3.031,42$ & 880,79 & $8.234,6$ & 794,15 & Sin \\
\hline $\begin{array}{l}\text { Principal país } \\
\text { importador }\end{array}$ & Alemania & Cuba & Reino Unido & Colombia & Irlanda & 947,4 \\
\hline
\end{tabular}

Fuente: Anuarios de Comercio Exterior de la República Argentina. 
Los datos de la Tabla 3 han sido sacados de un libro de recetas distribuido por una empresa pesquera con intención de promover el consumo de los productos del mar.
Según el Censo pesquero de 1941, la pesca para consumo humano, ya fuera fresco, salado o elaborado en conserva, presentaba la siguiente estructura (Tabla 4):

Tabla 3. Vendedores mayoristas remitentes al interior.

\begin{tabular}{|c|c|}
\hline Cimino Luis & Mercado del Pilar, Santa Fe 1970 \\
\hline Cogliandro Miguel & Mercado de Liniers \\
\hline Di Cugno Gerónimo y Nicolás & Mercado de Abasto del Sur \\
\hline De Rosa Antonio y Cía. & Mercado Ciudad de Buenos Aires \\
\hline Dinatale Rafael & Mercado Ciudad de Buenos Aires \\
\hline Fontana F. e Hijos & Morán 3347 \\
\hline Fuentes y Cía. & Mercado Eugenio Ben \\
\hline García Arturo Eloy & Mercado de Abasto Sud \\
\hline Gestore Juan & Mercado de Abasto \\
\hline Guido Miguel & Mercado Concentración Sud Puesto 16 \\
\hline Leiro Marcelino & Mercado del Plata \\
\hline Lizarraga y Gargiulo & Mercado General Roca \\
\hline Medrano Germán & Mercado Abasto del Sud \\
\hline Mellino Hermanos & Mercado del Plata \\
\hline Meo Felix y Cía. & Mercado Abasto del Sud \\
\hline Pérsico Eduardo & Mercado Ciudad de Buenos Aires \\
\hline Rodogno L. Hermanos & Mercado Ciudad de Buenos Aires \\
\hline
\end{tabular}

Fuente: Libro de Recetas de Cocina de la Empresa Gardella S.A. (no conserva datos de imprenta).

Tabla 4. Clasificación de la actividad pesquera según sus fuerzas productivas.

\begin{tabular}{|l|c|c|c|c|c|}
\hline Rubro & Altura & Costera & De laguna & De río & De embalse \\
\hline Embarcaciones & 11 & 227 & 66 & 165 & 3 \\
\hline Explotaciones & 5 & 227 & 53 & 177 & 3 \\
\hline Pescadores & 189 & 1.033 & 152 & 366 & 8 \\
\hline
\end{tabular}

Fuente: Censo de Pesca y Caza Marítima, ley 12.343/41, Ministerio de Agricultura y Ganadería de la Nación, Buenos Aires, 1941.

Si bien el censo registra cinco sociedades, las fuentes oficiales nos han permitido rescatar ocho empresas dedicadas a la pesca de altura, que operaban en la costa bonaerense, dedicadas especialmente a la extracción de corvina y pescadilla (Tabla 5). 
Tabla 5. Sociedades que comenzaron sus actividades entre 1936 y 1941.

\begin{tabular}{|c|c|c|}
\hline Empresas & Período de actividades & Barcos Pesqueros \\
\hline Pesquerías Gardella S.A. (Pesgar S.A.) & $1936 / 1942$ & $\begin{array}{c}\text { Delia } \\
\text { Angélica } \\
\text { Trucha } \\
\text { Blanca } \\
\text { Undine } \\
\text { Maneco } \\
\text { Bigüá } \\
\text { Tito }\end{array}$ \\
\hline $\begin{array}{l}\text { Industria Pesquera Argentina S.A. } \\
\text { (en } 1938 \text { los buques pasaron a integrar la } \\
\text { flota de Pesquerías Gardella S.A.) }\end{array}$ & $1936 / 1937$ & $\begin{array}{c}\text { Pescadilla } \\
\text { Corvina } \\
\text { Merluza } \\
\text { Besugo } \\
\text { Lenguado }\end{array}$ \\
\hline C. Lunblad, V. Guirovich y R. Ersini & $1936 / 1939$ & No se registran buques \\
\hline H. Fonda, P. Carucci y V. Arzubiaga & $1941 / 1949$ & Golondrina \\
\hline $\begin{array}{l}\text { Cía Argentina Comercial e Industrial de } \\
\text { Pesquerías S.A. (C.A.C.I.P.) }\end{array}$ & $1936 / 1949$ & No se registran buques \\
\hline $\begin{array}{l}\text { Pesquerías Argentinas Riomar (S.R. } \\
\text { Ltda.) }\end{array}$ & $1938 / 1951$ & Cristo de Limpias Don Bosco \\
\hline África Río de la Plata & $1938 / 1939$ & Sentinel II \\
\hline Industria Argentina de Pesca Plate y Cía. & $1940 / 1942$ & Gamma \\
\hline
\end{tabular}

Fuente: Armando Sangiorgio (1959).

Estas empresas por lo general se dedicaban solamente a la captura. Solo dos de ellas, Gardella y la Compañía Industrial de Pesquerías (C.A.C.I.P.), contaban con frigorífico a bordo. Esta última estaba integrada por capitales argentinos y japoneses y dado su conocimiento del mercado internacional, era la única que estaba en condiciones de aventurar pequeñas exportaciones de pescado fresco.

A partir de 1933 los Anuarios de Comercio Exterior registraron exportaciones de pescado fresco y en 1937 de pescado seco y conservado. En 1931 y 1932 el derecho aduanero de exportación de productos pesqueros era de un 2\%; a partir de 1933 se liberan de aranceles, mientras que el arancel aplicado a las importaciones oscilaba entre el 5 y el $12 \%$ y, en algunos casos, el $22 \%$. Sumado a esto, las prioridades consignadas por la Comisión de Control de Cambios dejaban un escaso margen para la importación de productos pesqueros mientras que una divisa libre para las exportaciones no tradicionales permitía un tipo de cambio estimulante para la comercialización de pescado conservado. Estas medidas funcionaron como impulso para la transformación de agencias exportadoras de conservas en fábricas elaboradoras (Masid, 2007) orientando a dos firmas importadoras, Benvenutto e Hijos ("La Campagnola") y Panebianco ("Cascabel”) en la ruta de la elaboración de productos de la pesca y su distribución en el mercado interno.

En realidad, el volumen de las exportaciones tenía una mínima incidencia en relación a la producción total de pescado fresco y elaborado, pero su rasgo destacable es la continuidad y la diversidad de los mercados de destino. En 1933 se exportaron apenas 51,44 toneladas de pescado fresco a 13 países. Los principales importadores eran Alemania, España, Francia, Italia, Reino Unido y Uruguay; en 1936 se exportaron 118,04 toneladas a 23 países, Alemania y 
el Reino Unido fueron los principales compradores; en 1937 se incorporó la exportación de pescado salado y conservado, se comercializaron 159,3 toneladas y en 1938, 365,48 toneladas, exportadas a 24 países de los cuales los principales compradores eran Brasil, Estados Unidos y Alemania; en 1940 las exportaciones ascendían a 456,16 toneladas y se mantenían los mismos mercados; finalmente, en 1943 se comercializan 1.609,3 toneladas de pescado a 39 países, siendo los principales compradores la Unión Sudafricana, Holanda, Brasil y Estados Unidos (Dirección General de Estadística de la Nación, 1933 y pass.).

Resumiendo, podemos observar que entre 1933 y 1943, la producción de pescado fresco, salado y conservado se insertó en el circuito de las industrias protegidas, con una participación mínima pero sostenida en el comercio exterior. Si además incluimos las exportaciones de guano y aceite de pescado, y las exportaciones de harina de pescado que comenzaron a registrarse en 1941 y gozaron de las mismas exenciones arancelarias, rescatamos la participación de todos los rubros que integran la industria pesquera. Participación significativa si se tienen en cuenta los rasgos destacados precedentemente, y que a la vez revela una dinámica empresarial atenta a las oportunidades.

Una última relación que vamos a establecer es la del total de las capturas y las exportaciones pesqueras.

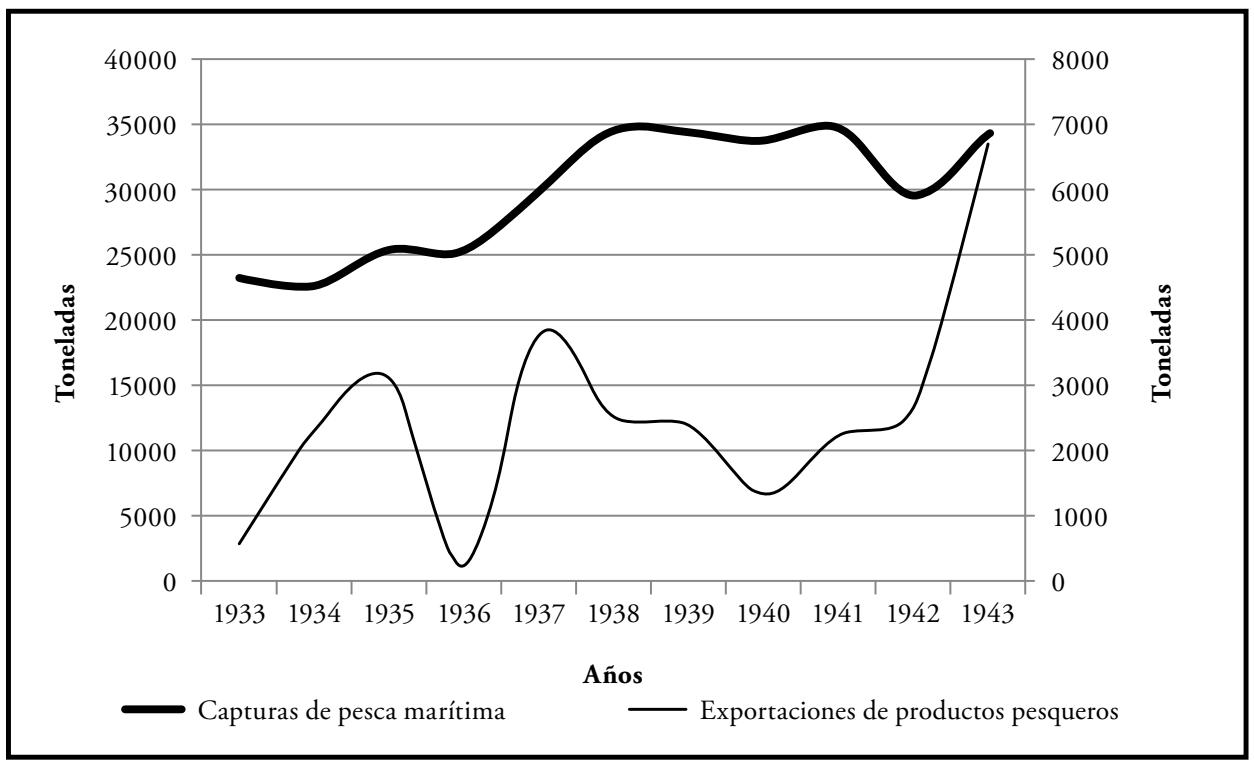

Figura 1. Relación entre las capturas (eje principal) y las exportaciones (eje secundario) en el período 1933-1943. Fuente: Elaboración propia con datos del Ministerio de Agricultura en Publicación Miscelánea, varios números y Anuarios de Comercio Exterior de la República Argentina.

Como puede observarse (Figura 1), las exportaciones, que en el mejor momento alcanzaron al 20\% de las capturas, siguen dos derroteros que solo ocasionalmente coinciden. Al parecer, ocasionalmente también, la demanda de la industria conservera estimuló la extracción. Algo bastante diferente ocurrió durante la Segunda Guerra Mundial, que originó una demanda insospechada hasta entonces de algunos productos pesqueros.

\section{Vitaminas y mercado interior}

“...ya sea porque nuestros productos, anualmente en aumento, van ganado mercado interno, ya por el elevado costo de producción extranjero, lo cierto es que vamos camino de cesar con estas importaciones dando amplitud de mercado al producto nacional" (Rossani, 1935, p. 88). 
Arrastrado por la realidad más que por política económica, la relación de Argentina con el mercado mundial comenzó a transformarse luego de la Gran Guerra. Durante la década del veinte, y como hemos dicho sobre todo desde 1930, la capacidad de obtener divisas para importar fue crecientemente deficitaria, ya fuera vía arancelaria o vía empréstitos. Como vimos, se intentaron una serie de medidas fiscales en función de aliviar las arcas del Estado que, como correlato, fue generando una industrialización sustitutiva de la importación que fue cubriendo algunos nichos de demanda dejados por la disminución de la posibilidad de obtener productos importados. E incluso alcanzando a la demanda externa.

Cuando confluyeron las dificultades de abastecimiento con la crisis del modelo agroexportador y el desarrollo de una incipiente industrialización de la pesca -a finales de los años treinta-, las empresas manufactureras de derivados pesqueros se beneficiaron con el arancelamiento de las importaciones y con la libertad cambiaria a las no tradicionales exportaciones de derivados pesqueros. Pasaron entonces a abastecer al mercado interior con conservas de pescado, pero todavía con niveles de captura muy modestos. Además, por esos años, a la venta en las ferias y a la venta ambulante se sumaron las de aquellos locales especializados, las "pescaderías", asentadas en algunas ciudades.

El efecto de la Segunda Guerra Mundial es claro. En la Figura 2 se observa el cruce de tijeras que se produjo hacia 1941 cuando las exportaciones tuvieron un salto cuantitativo, rompiendo la barrera de las 2500 toneladas para llegar a 6700 en 1943.

La mayor caída de las importaciones se dio en los arenques ahumados, sardinas y en las anchoas, coincidentemente con un mayor desarrollo de la conserva. Esto seguramente se debió tanto a las dificultades para importar como al desarrollo de la industria conservera en Mar del Plata. Desde la instalación en 1919 de "La Marplatense", la primera fábrica de conservas de pescado del puerto, ubicada junto a la escollera sur, se fueron instalando algunos saladeros familiares de anchoas. La salazón de anchoas era una actividad complementaria a otras formas de renta. La década del treinta se inicia con el auge de los saladeros de anchoítas organizados principalmente por emprendedores de apellidos italianos, o más precisamente marquellanos, sicilianos y napolitanos: Pisani, Panebianco, Spina (Figura 3), Gentile, Romeo,

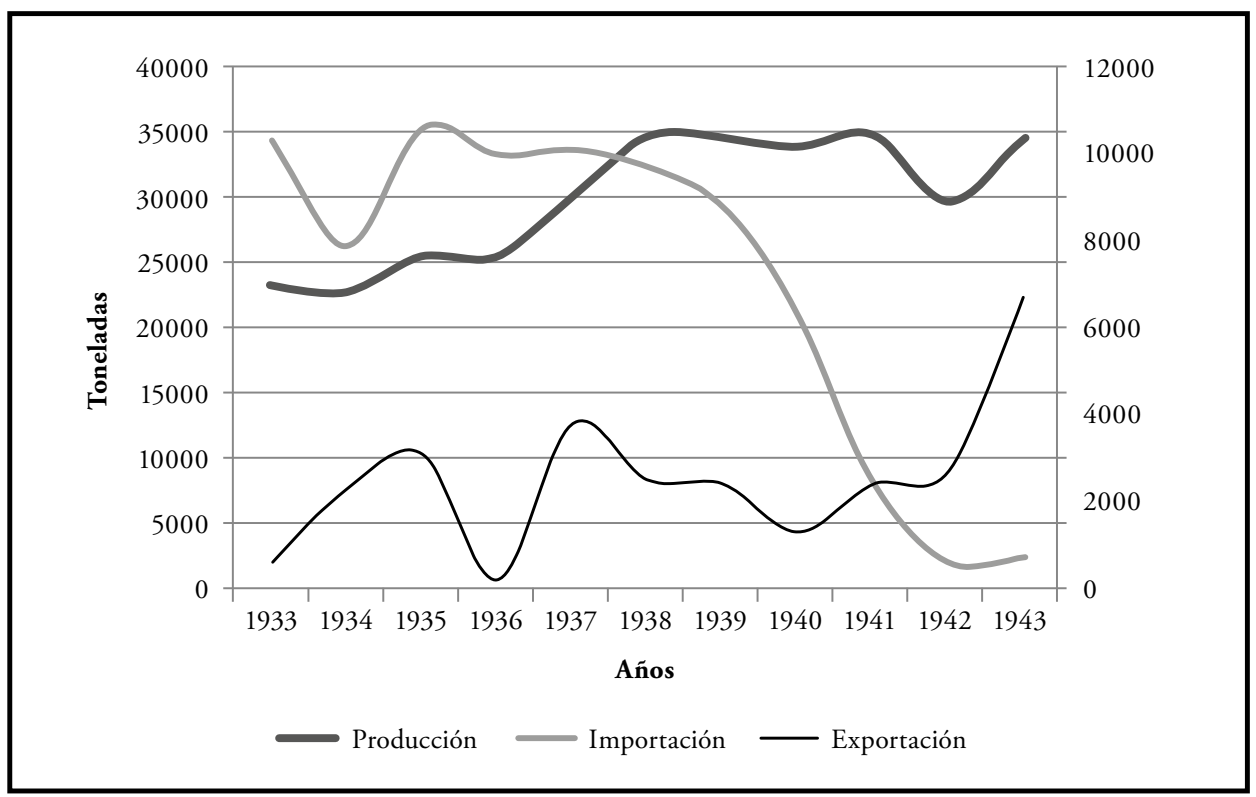

Figura 2. Relación entre la producción de derivados pesqueros (eje principal) y las exportaciones e importaciones (eje secundario) en el período 1933-1943. Fuente: elaboración propia con datos del Ministerio de Agricultura en Publicación Miscelánea, varios números. 


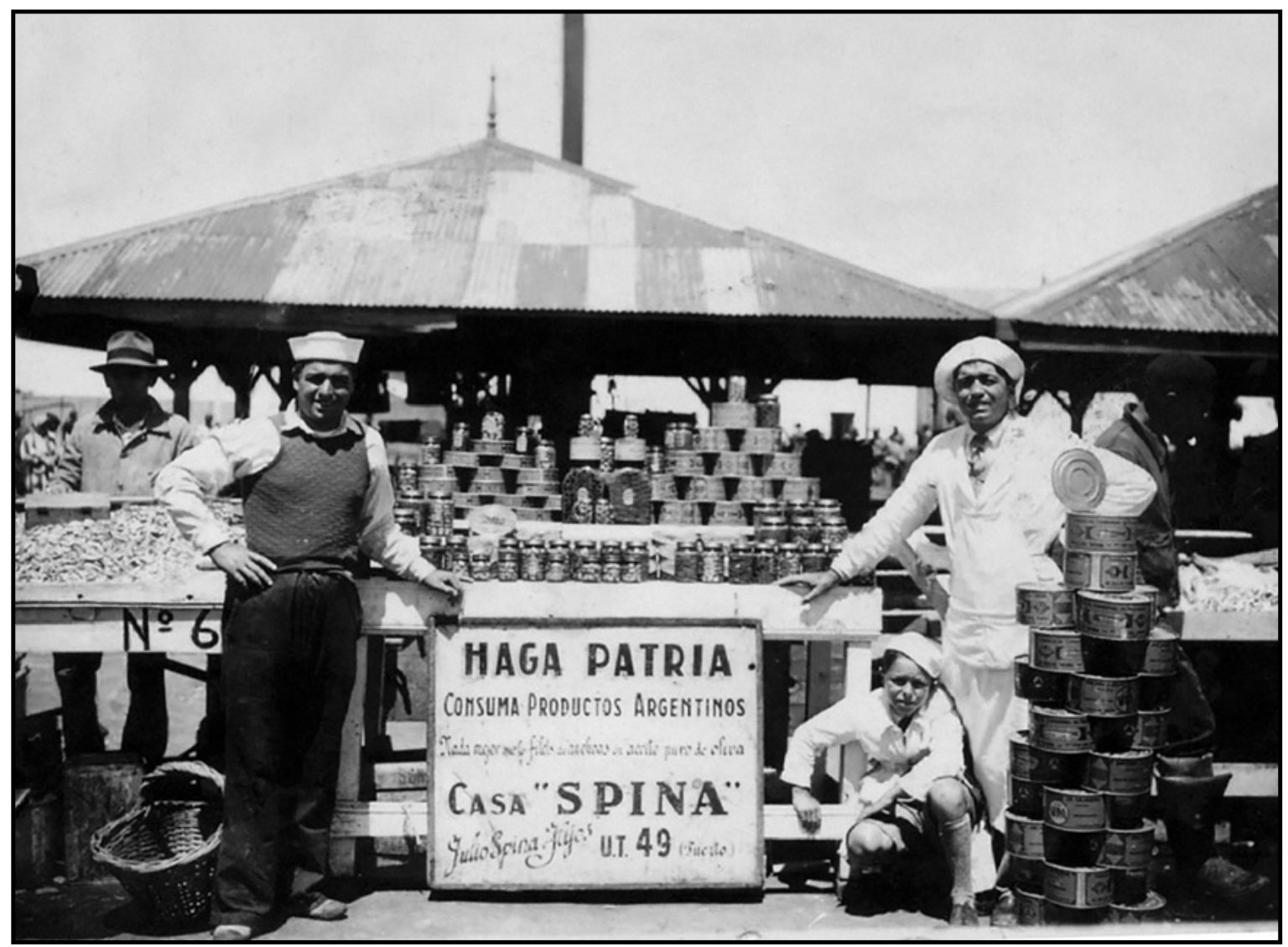

Figura 3. Fábrica de conservas Spina (gentileza Museo del Hombre del Puerto, Mar del Plata).

Belfiore, Santagati, Spoto, Buono, Di Meglio, Carbone, Pellegrino, Di Scala, Sinagra, Rua, Speranza, Greco Puglisi. Algunos de estos saladeros devinieron en fábricas de conserva (Mateo, 2004, p. 312).

La fábrica que rápidamente hegemonizó la conserva fue "La Campagnola", de la familia Benvenutto. Unos años más tarde se instalarían otras también relevantes como "Macchiavello y Cía.", "Mares del Sud", "Pulgar Hnos.", "Giacomo S.A.”, "Molfeta”, etcétera. A principios de la década del cuarenta, "La Campagnola" -que empleaba a 500 operarios-, "La Marplatense" -que ocupaba a 300-, "Mares del Sud" y Pulgar Hnos. -con 150 trabajadores cada una- eran las empresas líderes.

Todo un símbolo del fin de una época. Sin embargo, algunos derivados pesqueros no pudieron ser sustituidos, pero su importación disminuyó considerablemente. Las importaciones de ostras se redujeron un $23 \%$ entre 1929 y 1933 y las de caviar, un $41 \%$ (Rossani, 1935).

El desarrollo de una industria conservera sustitutiva derivó en el crecimiento de una industria pesquera integrada que se desarrollaba lenta pero ininterrumpidamente hasta que una demanda coyuntural, la de aceite de hígado de tiburón en su variedad cazón (Galeorbinus vitaminicus), permitió un salto cualitativo en todos los aspectos vinculados con la actividad pesquera (Mateo, 2006). La demanda de hígado de tiburón, cuyo valor pasó de aproximadamente 40 dólares la tonelada a valores que rondaban en los 2 mil, produjo una verdadera "fiebre" de captura.

¿A qué se debía esta demanda inusual y frenética? Tal aproximación a la pesca intensiva del tiburón tuvo su origen en dos coyunturas. En primer lugar, la Segunda Guerra Mundial interrumpió la pesca en los "Grandes Bancos" de Terranova y en el mar del 
Norte, caladeros históricos del bacalao, que era por entonces teatro de operaciones bélicas. Como señala Álvaro Díaz de la Paz (1988) para España: "El conflicto bélico había privado a la flota hispana del acceso a sus tradicionales caladeros del Norte europeo y, por tanto, al principal artículo de consumo básico de espańoles, portugueses, griegos e italianos, el bacalao. Había que buscar especies alternativas que pudieran satisfacer esta demanda y, al menos, coyunturalmente, esta se encontraría en las aguas saharianas: el 'bacalao español'”.

En segundo lugar, la misma logística de la guerra incrementó la necesidad de los complejos vitamínicos extraídos de este gádido. En el intento de hallarle un sustituto al tradicional cod liver oil, se descubrió que la concentración de unidades vitamínicas A en el aceite del hígado de algunos tiburones era incluso varias veces superior a la del bacalao.

Se había demostrado que la vitamina A era esencial en la vida de los mamíferos, aves y reptiles y que el síntoma característico de la avitaminosis A en el ser humano era "un largo umbral visual", es decir, una adaptación muy lenta a la oscuridad. En grados más agudos se producía una desecación de las glándulas sebáceas, produciéndose así muchas infecciones locales, especialmente en los ojos, pudiendo provocar ceguera definitiva. Además de que la vitamina A reducía la susceptibilidad al resfrió, tenía también efectos sobre el sistema nervioso (Mateo, 2006, p. 126).

El complejo vitamínico del aceite de hígado de tiburón permitía combatir la "preceguera nocturna". De ahí su importante aplicación en tiempo de guerra para aumentar la capacidad visual en la oscuridad, cuya carencia era uno de los primeros síntomas que afectaba a los aviadores y a los conductores de automotores y lanchas de asalto en la Segunda Guerra Mundial.

Argentina no permaneció indiferente al estímulo, y por los ańos cuarenta del siglo pasado muchos para quienes el mar era una abstracción se transformaron en pescadores, e incluso en prósperos pescadores seducidos por la fiebre del tiburón. Como correlato de esta incipiente industria, en 1944 el aceite de hígado de tiburón apareció como rubro de comercio exterior.
El comportamiento de esta exportación durante la coyuntura se puede observar en la Tabla 6 .

En la Figura 4 podemos observar cómo la captura fue estimulada por la exportación, y su caída acompańada con la de las exportaciones, al punto de que en 1953 desaparece momentáneamente como rubro de exportación.

Hacia 1945, durante el gobierno que depuso a la Concordancia, haciéndose eco de las posibilidades de esta actividad la Corporación para la Promoción del Intercambio (en adelante CPI), una institución multisectorial creada para promover exportaciones hacia los Estados Unidos unos años antes, difundió un conjunto de informaciones sobre la naciente industria del aceite de hígado de tiburón, con el propósito de colaborar con quienes habían "creado una nueva fuente de recursos" y una actividad útil para numerosas personas dedicadas a la pesca, quienes, "inesperadamente" ante las necesidades de la guerra, hallaron un "más provechoso empleo de su capacidad, su energía y de sus implementos de trabajo" (Presidencia de la Nación. Ministerio de Asuntos Técnicos, 1945).

¿Qué era esta corporación? La experiencia de la Gran Guerra generó la idea en los referentes de la economía argentina de mediados del siglo XX (Federico Pinedo y Raúl Prebisch) de que el problema fundamental en la Segunda Guerra Mundial serían los "excedentes invendibles de productos agrarios." A la inversa, era la oportunidad para iniciar la exportación de artículos nuevos de origen industrial. En este sentido, y a pesar del fallido destino político del plan económico de 1040 propuesto por el ministro Pinedo (Llach, 1984), el Estado de la Restauración Conservadora posibilitó que "un núcleo de hombres de negocios estrechamente vinculados al comercio argentino-norteamericano alcanzara el monopolio de la venta de divisas producidas por la exportación de productos no tradicionales a quienes deseaban adquirir productos importados sujetos a restricciones" (Decreto Ley 90.235 del 9.02.1941 publicado en el Boletín Oficial el 29.05.1941). Con esto se procuraba promover la exportación de origen industrial y fomentaba la compra de productos en los Estados Unidos. Los directorios de esta Corporación -que en la práctica adquirió la forma de una 
Tabla 6. Exportaciones de aceite de hígado de tiburón en toneladas métricas (tm).

\begin{tabular}{|c|c|c|c|c|c|c|c|c|c|}
\hline \multirow{2}{*}{ País importador } & \multicolumn{9}{|c|}{ Año } \\
\hline & 1944 & 1945 & 1946 & 1947 & 1948 & 1949 & 1950 & 1951 & 1952 \\
\hline Alemania & & & & 1 & 1 & & & & \\
\hline Brasil & 100 & 100 & 565 & & & & & & \\
\hline Chile & 99 & 3586 & 489 & 190 & & & & & \\
\hline Dinamarca & & & 953 & 1193 & 2641 & & & & \\
\hline Estados Unidos & 217076 & 249527 & 247847 & 86398 & 91999 & 15956 & 19234 & 3597 & \\
\hline Francia & & & 0 & 73781 & 62976 & 20662 & 7235 & 4632 & 3813 \\
\hline Italia & & & 3070 & & & & & & \\
\hline México & & 5 & 10 & & & & & & \\
\hline Noruega & & & & 3232 & & & 2468 & & \\
\hline Países Bajos & & & & 575 & & & & & \\
\hline Reino Unido & & 25 & 16430 & 93001 & 1712 & & & & \\
\hline Suecia & & 179 & 3600 & & 2820 & & & & \\
\hline Suiza & & & 4 & 3509 & & & & & \\
\hline Uruguay & 5200 & & & & & & & & \\
\hline Venezuela & 100 & & 217 & 90 & 244 & 140 & 150 & 130 & 50 \\
\hline Totales & 222575 & 253422 & 273185 & 261970 & 162393 & 36758 & 29087 & 8359 & 3863 \\
\hline
\end{tabular}

Fuente: Anuarios de Comercio Exterior de la República Argentina.

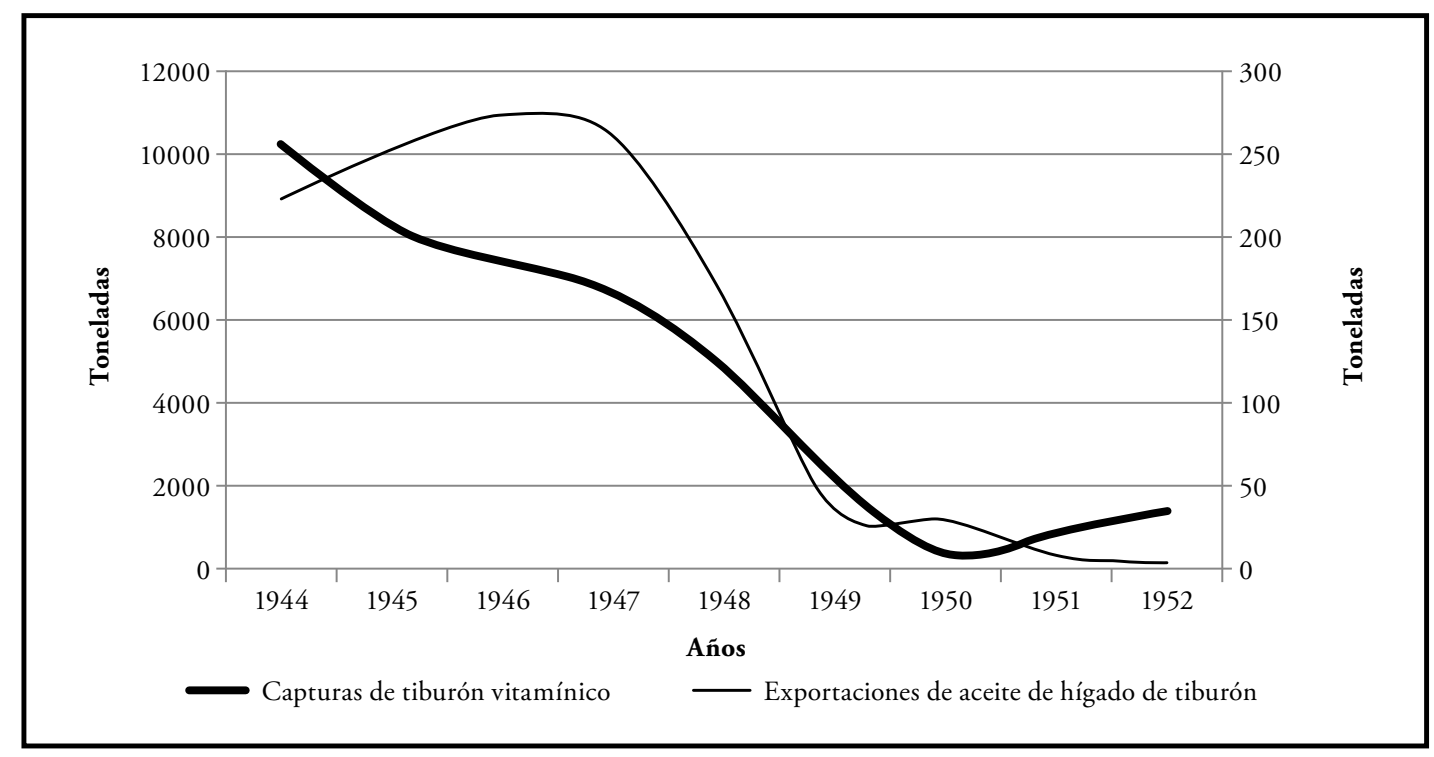

Figura 4. Relación entre las capturas de tiburón vitamínico (eje principal) y las exportaciones de aceite de hígado de tiburón (eje secundario) en el período 1944-1952. Fuente: Elaboración propia con datos del Ministerio de Agricultura en Publicación Miscelánea, varios números y Anuarios de Comercio Exterior de la República Argentina. 
sociedad anónima- estuvieron ocupados por altos directivos de las empresas norteamericanas con filiales en el país, por banqueros y por empresarios industriales tradicionales con "aptitud exportadora". Entre los primeros se destacan los presidentes del City Bank, General Electric, General Motors, Ford Motors, Banco de Boston y Cámara de Comercio Estadounidense. De entre los miembros nativos figuran los apellidos Bemberg, Tornquist, Bunge y Born y Braun Menéndez.

La CPI fracasó rápidamente debido a la falta de transportes y a la selectividad negativa creciente de Estados Unidos con respecto a los productos provenientes de la Argentina. La institución se abocó entonces a realizar estudios "con vistas a las actividades a desarrollar en el futuro" integrados en el Informe Armour (Corporación para la Promoción del Intercambio, 1982). El informe proponía líneas de producción con mejores ventajas comparativas tales como la elaboración de cemento y cal, ganado porcino, lácteos, cereales, lana, algodón, madera, plomo y zinc, y químicos (soda cáustica y ácidos).
También algunas industrias más elaboradas como la bodeguera, papelera, calzado y frigorífica.

Por intermedio de sus sucursales en los Estados Unidos, la corporación observó el interés creciente de ese mercado por el aceite de hígado de tiburón como fuente de vitamina A en reemplazo del de bacalao. Promovieron entonces la creación de negocios de exportación hacia los Estados Unidos, apoyada en material bibliográfico referido tanto a la pesca misma como a la captura, la obtención del aceite y su refinación posterior y el aprovechamiento de cueros y carne, etcétera, proveniente tanto de los Estados Unidos como de otros países donde esta industria alcanzó cierto desarrollo. Este material, a juzgar por el rápido impulso que alcanzó la actividad, debió ser cabalmente aprovechado (Figura 5).

Pero no todo terminaba en las vísceras del tiburón. Del mismo modo que la ballena, el tiburón era íntegramente aprovechado por la industria. La carne era utilizada como alimento humano, vendida fresca en algunos mercados, además de salada y secada,

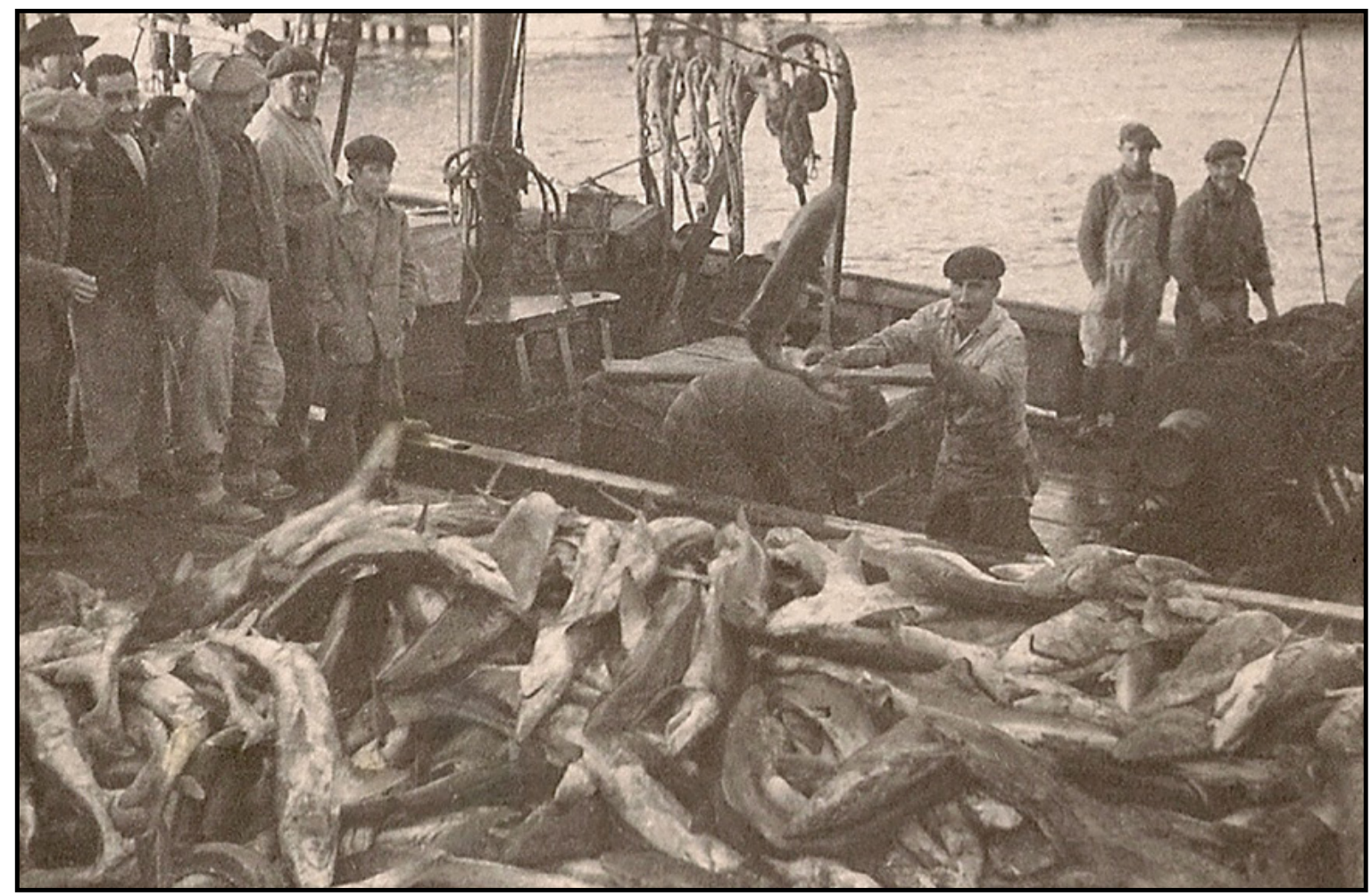

Figura 5. Pesca de tiburón vitamínico en Mar del Plata (gentileza Museo del Hombre del Puerto, Mar del Plata). 
preparándose con ella una conserva tipo bacalao. También se elaboraba harina de pescado y el cuero ofrecía un excelente material para la confección de calzado, carteras, etcétera. Sumado a ello, del tiburón se extraían pegamentos y gelatinas de apreciable valor comercial.

La demanda de tiburón apareció con la guerra y desapareció casi por completo una vez restablecida la paz y sintetizada la vitamina A por los laboratorios suizos Roche, aunque su calidad no podía contrarrestar la excelencia de la vitamina natural del hígado de tiburón. Este corto tiempo bastó sin embargo para crear pequeños capitales que se convertían en viviendas de pescadores, en lanchas pesqueras y en equipos industriales.

También afectó la forma de comercialización de la pesca. La producción de aceite de hígado de tiburón promovió tan fenomenal cambio en el movimiento pesquero, que este dejó de realizarse en la forma transaccional típica, para pasar de una operatividad rutinaria "a tarifa" - una suerte de cuota establecida por la demanda- con las especies destinadas para los saladeros y las fábricas, a una puja diaria del producto de sus pescas, incitándolos a extraer mayores volúmenes a la máxima brevedad ante los estimulantes precios de remate que las promovían.

La pesca costera, es decir, la operada dentro de las tres millas náuticas de la costa, saltó las barreras de las corporaciones locales, haciendo del negocio de la pesca una cuestión nacional en su fase extractiva e internacional en sus alcances comerciales. Se conjugaron en esta oportunidad los intereses privados externos a la pesca a través de su participación en las fases de elaboración y comercialización y el impulso, aunque más no fuera fiscal, del Estado. A estos se sumó una acumulación interna del propio productor que tuvo oportunidad de multiplicar sus fuerzas productivas (embarcaciones, artes de pesca, pescadores formados, puertos, conocimientos, etc.).

Cabe evocar ese pasaje de nuestro movimiento pesquero, fabril y comercial -incluso generador de divisas- como el que más ingentes beneficios económicos reportó a los propietarios y a los pescadores de las embarcaciones dedicadas a la pesca, que con el tiburón impulsaron el desarrollo de la actividad en la Argentina, auspiciando un prometedor futuro pesquero (Mateo, 2006, p. 140).

La oportunidad surgida a partir de la industria sustitutiva del tiburón permitió un salto cualitativo que estimuló la actividad pesquera en su conjunto y muy probablemente fue la causa de que la industria de Mar del Plata pudiera absorber y contener, con un éxito notable, el nuevo impulso dado a la pesca al desaparecer el interés por el tiburón.

Este fue uno de los pocos casos conocidos en que la actividad pesquera logró acumular capital y desarrollar fuerzas productivas en función del valor de sus capturas, sin la inversión directa de capital ni crediticia de sectores ajenos a la pesca, o del Estado.

Esta "fiebre", como todas ellas, tuvo su cara luctuosa. El tiburón vitamínico no solo fue la primera especie sometida a estrés de sobrepesca, sino que su captura produjo la mayor cantidad de pérdidas de vidas humanas que recuerda la actividad pesquera en Argentina (Mateo, 2015, p. 143).

\section{La segmentación del mercado}

Para 1950 la industria de la conserva y la salazón presentaba un notable desarrollo en el mercado interno y una participación importante en el mercado exportador, sin embargo, el tema del bajo consumo de pescado fresco en Argentina era una preocupación latente. La importancia de promover el consumo de pescado residía en su valor alimenticio en tanto sustituto de la carne vacuna como generador de proteínas animales, cuyo excedente era necesario incrementar debido a la necesidad del gobierno de obtener divisas a través de la exportación de carne de res. La política económica del peronismo había reservado en sus planes quinquenales un espacio para el desarrollo pesquero y la mira estaba puesta en la pesca de altura.

De acuerdo a lo establecido en el Segundo Plan Quinquenal, el gobierno tenía previsto incrementar en un alto porcentaje la producción y comercialización pesquera y el consumo de pescado fresco. En el plan se tomaron medidas proteccionistas orientadas directa o indirectamente a promover el consumo de 
la pesca nativa. Además, hubo vedas de carne los días viernes. Sin embargo, estas medidas no estimularon el consumo, las pescaderías siguieron siendo pocas y dispersas y los carniceros tuvieron aversión a expender pescado los días de veda (Mateo, 2005).

Entre 1949 y 1952 dos empresas belgas y una española se instalaron en Mar del Plata para dedicarse a la captura de pescado para consumo en fresco y sentaron las bases para la explotación de la merluza. Los barcos belgas (Figura 6), particularmente, estaban dotados de la tecnología suficiente para operar a grandes profundidades y permanecer un tiempo prolongado en el mar. Hasta su llegada, la flota fresquera estaba integrada casi totalmente por vapores que salían muy temprano en la mañana y regresaban al atardecer. La especie de merluza que se capturaba no era la misma que se comercializa actualmente. Sus exploraciones posibilitaron el descubrimiento de nuevos bancos de merluza, sobre todo de la merluza austral, especie cuyo valor comercial tendría un peso significativo en las futuras exportaciones de pescado fresco (Masid, 2004).
Las capturas de merluza se incrementaron, pasando de 9250 toneladas en 1950 a 19.696 toneladas en 1951 y 24.624 en 1952, según informaba en 1954 la Dirección General de Pesca y Conservación de la Fauna; sin embargo, subsistía el problema de la falta de instalaciones para la conservación del producto y de medios adecuados para el transporte de pescado (vagones y camiones frigoríficos). En tal sentido, el ingeniero Eduardo Quinterno solicitó en octubre de 1953 al ministro de Asuntos Técnicos, Dr. Mendé, autorización para utilizar la planta de congelación rápida, sistema "Ottesen", que poseía el frigorífico Eva Perón, situado en la dársena de pescadores del puerto de Mar del Plata, perteneciente al Ministerio de Agricultura y Ganadería. La intención de Quinterno era poner en marcha una organización de congelación de pescado y su distribución "de acuerdo a las más modernas exigencias de la ciencia, técnica e higiene". También solicita la adjudicación de seis acoplados "Dorsey" y dos unidades de tractores. Dichos elementos eran propiedad del Instituto Argentino para la Promoción del Intercambio, organismo creado por el gobierno revolucionario en 1945 para

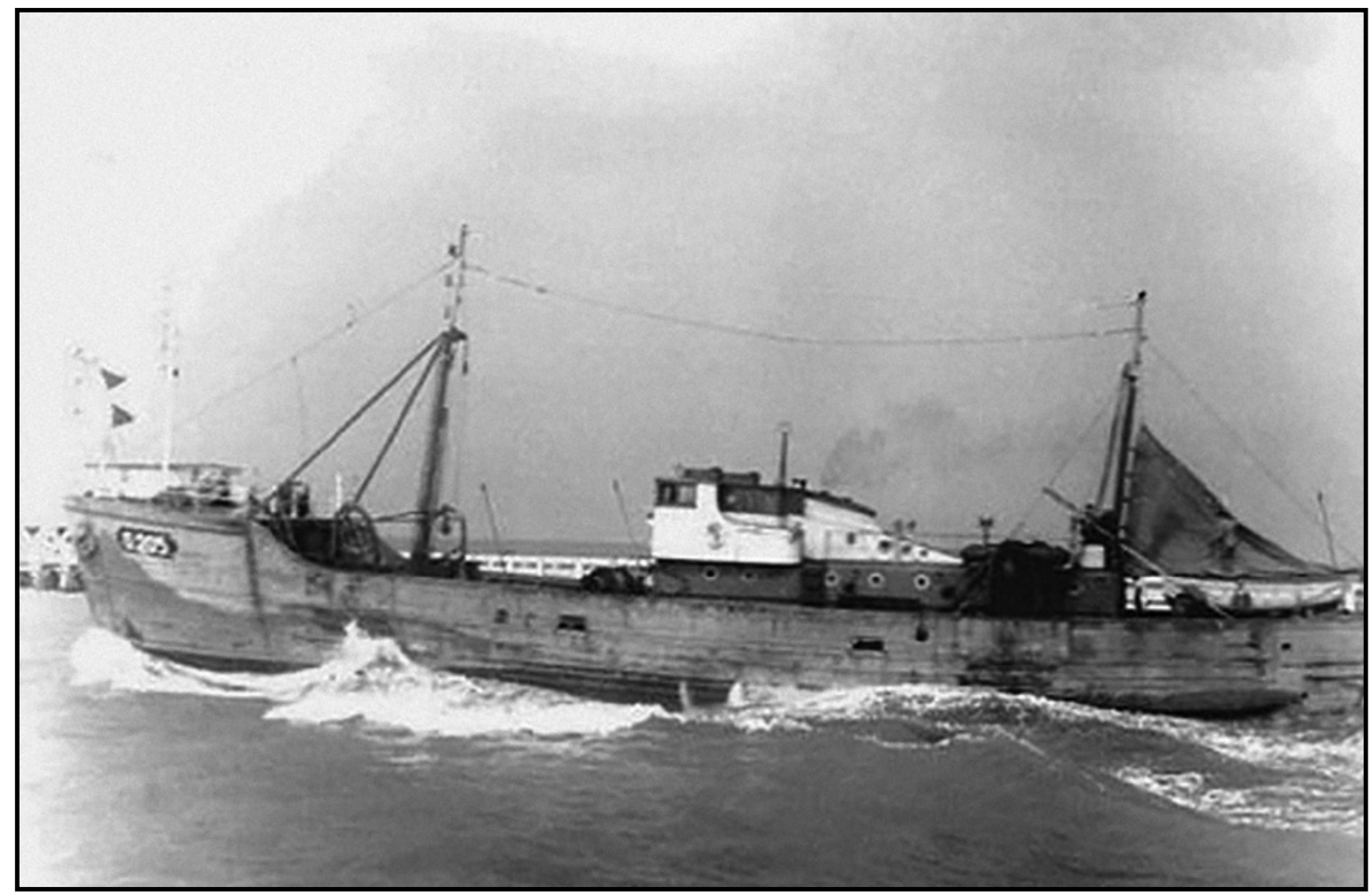

Figura 6. Buque belga Montreal (gentileza Museo del Hombre del Puerto, Mar del Plata). 
regular el comercio exterior; esto permitiría la rápida distribución del pescado congelado en óptimas condiciones de conservación. En el documento figuran inscripciones marginales que dan cuenta del trámite burocrático seguido, al parecer con escaso éxito (Mateo, 2011a).

En el marco de la política de financiamiento del Banco Industrial se otorgaron créditos al sector pesquero, que solo beneficiaron a las industrias con mayor respaldo financiero: Benvenutto S.A. (La Campagnola), Pesquería Argentina de los Mares del Sur y Compañía Argentina de Pesca (Rougier, 2001). Algunas empresas se beneficiaron con el otorgamiento de créditos acordados dentro de la política global de financiamiento a la industria de bienes de consumo orientados al mercado interno. Entre 1948 y 1970 el Banco Industrial de la República Argentina (luego Banco Nacional de Desarrollo) otorgó para la industria pesquera 1150 operatorias (Alomar, 1973).

Durante el gobierno peronista (Figura 7) se mantuvieron las exportaciones de pescado, pero cambió la tendencia: a medida que aumentan las capturas, decrecen las exportaciones. Los principales países importadores eran Espańa, Brasil, Italia, Reino Unido y Estados Unidos.
El plan de acción del gobierno de Arturo Frondizi, inspirado en las tesis del desarrollismo, se orientó decididamente a fomentar aquellas actividades que garantizaran el paso hacia una economía industrial. Las industrias centrales del programa eran las químicas, las petroquímicas y la siderurgia. Las industrias extractivas y manufactureras quedaron en una primera instancia rezagadas, sin embargo, las políticas de estímulo a la industria del transporte posibilitaron su expansión. La construcción de una red vial y la incorporación de medios de transporte posibilitaron la integración económica de las regiones del país y la descentralización de las actividades económicas. Entre 1958 y 1961 se produjo un incremento del $80 \%$ en la industria manufacturera (Gerchunoff y Llach, 2010, p. 256).

Por su parte, la industria pesquera supo acoplarse estratégicamente a sus políticas de financiamiento. En la década del sesenta tres factores convergieron para producir el primer gran cambio estructural del sector pesquero: nuevas formas de presentación del pescado fresco en el mercado consumidor, el acceso a ventajosas fuentes de financiamiento $y$ la oportunidad de insertarse en condiciones favorables en el mercado internacional. La merluza sería esta vez la especie propiciatoria. Su captura

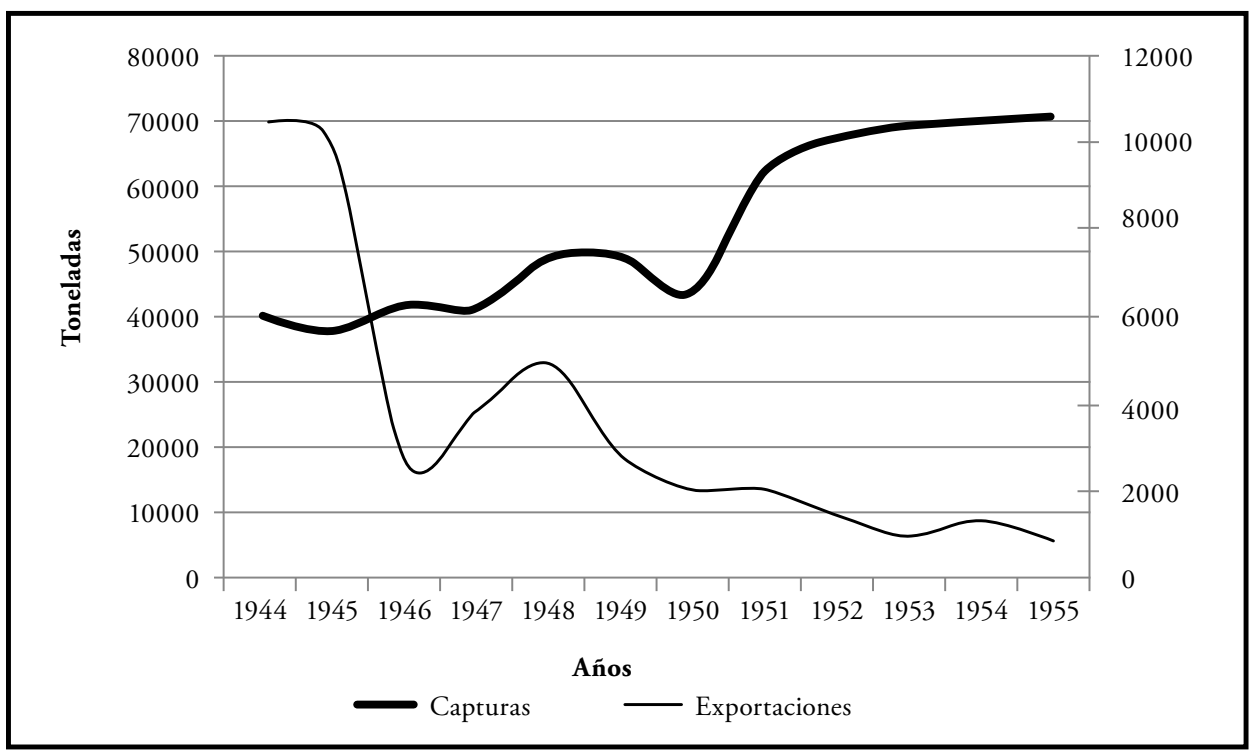

Figura 7. Relación entre las capturas (eje principal) y las exportaciones (eje secundario) en el período 1944-1955. Fuente: Elaboración propia con datos del Ministerio de Agricultura en Publicación Miscelánea, varios números y Anuarios de Comercio Exterior de la República Argentina. 
abundante promovió a principios de la década el procesamiento industrial del "filet", generando una expansión de la demanda interna (hasta ese momento el pescado se vendía entero y era el expendedor quien lo evisceraba y fileteaba enfrente del comprador). El auge del producto exigió la instalación de cámaras congeladoras en las plantas de fileteado. La iniciativa fue fortalecida por la política crediticia del gobierno de Arturo Frondizi, que al incluir la industria naviera entre las beneficiarias de créditos para la renovación de los medios de transporte, posibilitó el crecimiento de la flota fresquera.

En 1958 fue autorizada la concesión de créditos a armadores o propietarios de barcos para la construcción y modernización de buques y embarcaciones (Decreto-ley 3115/58). Los primeros créditos fueron otorgados a principios de 1960 por intermedio del Banco de Crédito Industrial y estaban destinados al equipamiento de la flota de la Marina Mercante, que incluía a la flota pesquera. La Flota Mercante del Estado se creó después de la Segunda Guerra, "con la confiscación de barcos de países beligerantes que se hallaban en puertos argentinos a comienzos de la misma" (Rapoport, Madrid, Musacchio, y Vicente, 2012, p. 441). Posteriormente el financiamiento se extendió a las empresas privadas. Los armadores y consignatarios se integraron al circuito industrial. Las plantas se expandieron y las empresas se diversificaron. La unidad productiva absorbió simultáneamente la captura, la industrialización y la comercialización del producto.

La articulación al comercio internacional en condiciones más ventajosas se originó con la crisis de los tradicionales caladeros del Mar del Norte. El proceso de sobrepesca que comenzó a manifestarse en los años cincuenta promovió la demanda de pescado blanco de caladeros no tradicionales (Cushing, 1975; Holm, 1998). La difusión del valor nutritivo del pescado entre los consumidores extranjeros y un cambio en los patrones de consumo permitieron la inserción de la merluza argentina en el mercado exportador. El margen de capacidad ociosa de las plantas alentó al sector industrial a orientar el excedente hacia el mercado externo. La industria elaboradora se reactivó en un $170 \%$. Considerando un aumento del $206 \%$ en la producción de harina de pescado, los volúmenes de la exportación se incrementaron en un 300\% con relación a años anteriores (Espoz Espoz, 1985, p. 75).

Sin embargo, la década del sesenta (Figura 8) debe considerarse de ensayo y error, sobre todo en los primeros años, porque la política exportadora fue improvisada y la adaptación tecnológica exigió fuertes

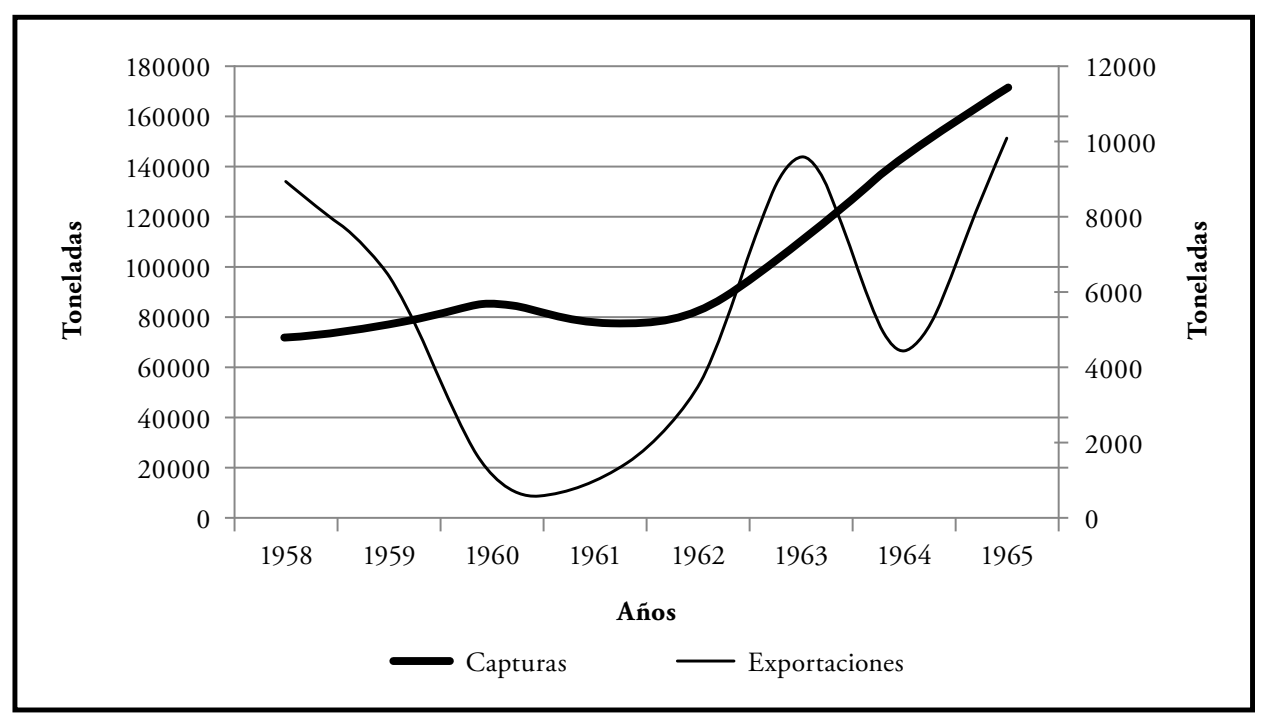

Figura 8. Relación entre las capturas (eje principal) y las exportaciones (eje secundario) en el período 1958-1965. Fuente: Elaboración propia con datos del Ministerio de Agricultura en Publicación Miscelánea, varios números y Anuarios de Comercio Exterior de la República Argentina. 
inversiones y el consiguiente endeudamiento. $\mathrm{Si}$ bien en el ámbito fiscal la aplicación de medidas impositivas y el reintegro de recargos de cambio y de derechos aduaneros aliviaron los problemas derivados de las importaciones de insumos, estas fueron entorpecidas por las continuas regulaciones cambiarias, a la vez que el proceso inflacionario alteraba los cálculos en los costos de producción (García Cabrejas \& Malaret, 1970).

Durante el gobierno de Arturo Illia se puso en marcha el "Plan de Fomento de la Pesca Marítima". El mismo surgió de la firma de un convenio de cooperación técnica y científica entre el gobierno argentino y la Organización de las Naciones Unidas para la la Alimentación y la Agricultura (FAO). Su objetivo era proyectar la ordenación del sector y promover el desarrollo de las principales especies marítimas. En 1964, la firma de un acuerdo con la Asociación Latinoamericana de Libre Comercio (ALALC) impulsó la actividad pesquera hacia el mercado regional. Estos acuerdos fueron resistidos por los industriales; ellos argumentaban que el otorgamiento de permisos de pesca a países extranjeros obtaculizaba la competencia de la industria nacional. Sin embargo, en 1964 las exportaciones presentaron un significativo incremento, sobre todo si se las relaciona con la de principios de la década, y se debió especialmente al comercio realizado con los países de la ALALC. El camino hacia nuevos mercados estaba trazado, el destino privilegiado de las capturas a partir de entonces se encontró en el exterior.

\section{Conclusiones}

Las etapas analizadas en el presente trabajo han revelado que la articulación de la industria pesquera al proceso de sustitución de importaciones fue temprana y gradual, y que en dicho proceso el sector presentó continuas transformaciones que evidencian su adaptación a distintas coyunturas y un oportuno aprovechamiento de las diferentes oportunidades que fueron surgiendo en su desarrollo. Señalamos en cada etapa los factores de imponderable importancia que estimularon la dinámica industrial: las medidas arancelarias "de emergencia" y "transitorias" implementadas por los gobiernos conservadores; una fase de acumulación de fuerzas productivas durante la coyuntura del tiburón, y las extendidas medidas de protección y apoyos estatales, directas e indirectas, durante las últimas fases de la sustitución de importaciones.

Sobre la base de una industria regional, y en algunos momentos netamente estacional y local, los datos estadísticos revelan, a partir de los años treinta, el lento pero sostenido crecimiento del sector pesquero y sus diversos rubros, y su inclusión dentro de las industrias protegidas por los beneficiosos instrumentos arancelarios del período. Asimismo, los Anuarios de Comercio Exterior revelan su inserción en el comercio exportador. Consecuentemente con los objetivos de su creación, la Corporación para la Promoción del Intercambio (CPI) fue el vehículo de las exportaciones y un activo dinamizador de las manufacturas pesqueras. Particularmente el aceite de hígado de tiburón, que en la mitad de la década del cuarenta ejerció un notable predominio en el mercado exportador y provocó la acumulación inicial de los productores pesqueros marplatenses y, como consecuencia, la reinversión de una parte considerable del capital en la industria elaboradora.

El aumento de las capturas durante el período manifiesta asimismo la introducción de know how y expertise producto de la inmigración post Segunda Guerra Mundial, que agilizaron las operaciones de altura, rezagadas por la falta de infraestructura adecuada, y la explotación de nuevas especies. El excedente de la captura de merluza y una nueva coyuntura (la sobrepesca en el Mar del Norte) van a dar origen, en los ańos sesenta, al primer gran cambio estructural en la industria pesquera, el procesamiento y la comercialización de pescado fresco y congelado. La industria pesquera argentina atrajo a partir de ese momento la atención de los importadores externos y es vislumbrada ella misma como generadora de divisas. Una oferta crediticia oportuna que favoreció la introducción de tecnología adecuada y la implementación de una política pesquera (no siempre acorde al proceso de desarrollo) orientaron netamente la industria hacia el mercado exportador. 


\section{Referencias citadas}

Alomar, J. (1973). El crédito para inversiones privadas. En Malaret, A. (Ed.). La Pesca Comercial en Argentina. Buenos Aires: Fundación Argentina de Estudios Marítimos.

Balsa, J. (2004). El Estado democrático y la gobernabilidad. Sus efectos en la sociedad. En A. Z. y J. B. Girbal, Noemí (Ed.). Estado, sociedad y economia (1930-1997) (pp. 197251). Quilmes: UNQ.

Bértola, L. y Ocampo, J. A. (2010). Desarrollo, vaivenes y desigualdad. Una historia económica de América Latina desde la independencia. Madrid: Secretaría General Iberoamericana.

Cañete, V. (2011). Instituciones y políticas públicas en la expansión pesquera de la Argentina, 1946-1976. Anuario - Centro de Estudios Economicos de la Empresa y el Desarrollo, 3(3), 207-253.

Corporación para la Promoción del Intercambio, S. A. (1982). "Informe Armour”. Desarrollo Económico, 22(85).

Cushing, D. (1975). Fisheries Resources of the Sea and their Management. United Kingdom: Oxford University Press.

Diaz Alejandro, C. F. (1979). Algunas vicisitudes históricas de las economías abiertas en América Latina. Desarrollo Económico, 19(74), 147-159.

Díaz de la Paz, Á. (1988). Las pesquerías canario-africanas a la luz de los estudios sobre el banco sahariano (19401975). Aula Canarias y el Noroeste de África, 3, 431-441.

Dirección General de Estadística de la Nación. (1933). Anuario del Comercio Exterior. República Argentina. Buenos Aires: Talleres S. A. Casa Jacobo Peuser.

Espoz Espoz, M. (1985). Introducción a la Pesca Argentina. Su rol en la Economía Nacional y Mundial. Mar del Plata, Argentina: Fundación Atlántica.

García Cabrejas, J. y Malaret, A. (1970). Análisis del comercio exterior de los productos pesqueros argentinos 1963 1968. Buenos Aires.

Gerchunoff, P. y Antúnez, D. (2002). De la bonanza peronista a la crisis del desarrollo. En Torre, J. C. (Ed.). Los años peronistas (1943-1955) (pp. 125-205). Buenos Aires: Sudamericana.
Gerchunoff, P. y Llach, L. (2010). El ciclo de la ilusión y el desencanto. Un siglo de politicas económicas argentinas. Buenos Aires: Planeta.

Holm, P. (1998). The Global Fish Market, 1850-1995. En Harlaftis, G. y Starkey, D. J. (Eds.). Global markets: the internationalisation of the sea transport industries since 1850 (pp. 239-258). Madrid: Fundación Fomento de la Historia Económica.

Llach, J. J. (1984). El plan Pinedo de 1940. Su significado histórico y los orígenes de la economía política del peronismo. Desarrollo Económico, 23(92), 516-558.

López, R. B. (1954). La pesca en la república Argentina durante el ańo 1952. Revista del Museo Municipal de Ciencias Naturales y Tradicional de Mar del Plata, 1(2).

Masid, M. (2004). Los pescadores flamencos de Mar del Plata, una aventura que comienza en Nieuwpoort. Estudios Migratorios Latinoamericanos, 18(54), 303-338.

Masid, M. (2007). El proceso de sustitución de importaciones pesqueras en la Argentina, durante la Gran Depresión: una visión desde las instituciones (1933-1943). En Primeras Jornadas de Historia de la Industria y los Servicios. Buenos Aires: Universidad de Buenos Aires.

Mateo, J. (2004). Cosechando el mar en lanchas amarillas. La expansión de la pesca costera marplatense (19391963). Anuario del IEHS, 19, 305-335.

Mateo, J. (2005). El período heroico de la pesca costera en Argentina (1940-1975). Lanús, Argentina: Universidad de Lanús.

Mateo, J. (2006). Sembrando anzuelos para tiburones: Las demandas vitamínicas de la II Guerra Mundial y el desarrollo de la pesca comercial marítima en Argentina (1943-1952). Boletin del Instituto de Historia Argentina y Americana Dr. Emilio Ravignani, 29, 119-150.

Mateo, J. (2011a). Separados por el mar, unidos por el mercado. En Alcalá Moya, G. (Ed.). Pescadores en América Latina y el Caribe: situación y perspectivas (pp. 251-316). México: Editorial de la UMDI de la Facultad de Ciencias de la Universidad Nacional Autónoma de México.

Mateo, J. (2011b). Un mar y tres fronteras para el desarrollo de la pesca en Argentina (1940-1975) (pp. 79-91). Mar del Plata, Argentina: RedeP-CONICET. 
Mateo, J. (2015). Gringos que montaban olas. Historia de la pesca costera en Argentina. Mar del Plata, Argentina: GESMar.

Mateo, J. y Yurkievich, G. (2010). Estrategias de la anchoíta en un mar de tiburones: Las pymes conserveras marplatenses durante la valoración financiera (1975-2006). Trabajos y Comunicaciones, 36, 141-164.

Míguez, E. J. (2005). El fracaso argentino. Interpretando la evolución económica en el «corto siglo XX». Desarrollo Económico, 44(176), 483-514.

Novick, S. (2004). Aspectos jurídico-politicos de los censos en la Argentina: 1852-1995 (Documentos de Trabajo núm. 39). Buenos Aires.
Presidencia de la Nación. Ministerio de Asuntos Técnicos. Documentación del Consejo de Posguerra (1945). Buenos Aires.

Rapoport, M., Madrid, E., Musacchio, A. y Vicente, R. (2012). Historia económica, política y social de la Argentina (1880-2003). Buenos Aires: Emecé.

Rossani, J. A. (1935). La pesca en la República Argentina. Buenos Aires: Ediciones ALBA.

Rougier, M. (2001). La politica crediticia del Banco Industrial durante el primer peronismo (1944-1955) (núm. 5). Buenos Aires.

Villanueva, J. (1972). EL origen de la industrialización argentina. Desarrollo Económico, 12(47), 451-476. 